\title{
Evaluation of three commercial bovine ELISA kits for detection of antibodies against Alphaherpesviruses in reindeer (Rangifer tarandus tarandus) Carlos G Das Neves*1, Matthieu Roger ${ }^{1,4}$, Nigel G Yoccoz², Espen Rimstad ${ }^{3}$ and Morten Tryland ${ }^{1}$
}

\begin{abstract}
Address: ${ }^{1}$ The Norwegian School of Veterinary Science, Department of Food Safety and Infection Biology, Section of Arctic Veterinary Medicine, Stakkevollveien 23, NO-9010 Tromsø, Norway, ${ }^{2}$ University of Troms $\varnothing$, Institute of Biology, NO-9037 Troms $ø$, Norway, ${ }^{3}$ The Norwegian School of Veterinary Science, Department of Food Safety and Infection Biology, Section of Microbiology, Immunology and Parasitology, PO Box 8146, NO-0033 Oslo, Norway and ${ }^{4}$ YROI: Cyclotron et Recherche Biomédicale Technopole - 2 Rue Maxime Rivière - BP 80005 - 97491 Sainte Clotilde Cedex, Island of Réunion
\end{abstract}

Email: Carlos G Das Neves* - carlos.neves@veths.no; Matthieu Roger - mattewrog@hotmail.fr; Nigel G Yoccoz - nigel.yoccoz@ib.uit.no; Espen Rimstad - espen.rimstad@veths.no; Morten Tryland - morten.tryland@veths.no

* Corresponding author

Published: 9 March 2009

Acta Veterinaria Scandinavica 2009, 5 I:9 doi:10.1 186/175I-0147-5I-9
Received: 10 July 2008

Accepted: 9 March 2009

This article is available from: http://www.actavetscand.com/content/5I/I/9

(C) 2009 Das Neves et al; licensee BioMed Central Ltd.

This is an Open Access article distributed under the terms of the Creative Commons Attribution License (http://creativecommons.org/licenses/by/2.0), which permits unrestricted use, distribution, and reproduction in any medium, provided the original work is properly cited.

\begin{abstract}
Background: The genus Varicellovirus (family Herpesviridae subfamily Alphaherpesvirinae) includes a group of viruses genetically and antigenically related to bovine herpesvirus I (BoHV-I) among which cervid herpesvirus 2 (CvHV-2) can be of importance in reindeer. These viruses are known to be responsible for different diseases in both wild and domestic animals. Reindeer are a keystone in the indigenous Saami culture and previous studies have reported the presence of antibodies against alphaherpesviruses in semi-domesticated reindeer in northern Norway. Mortality rates, especially in calves, can be very high in some herds and the abortion potential of alphaherpesvirus in reindeer, unlike in bovines, remains unknown.

ELISA kits are the most used screening method in domestic ruminants and given the close genetic relationship between viruses within this genus, it might be possible to use such kits to screen cervids for different alphaherpesviruses. We have compared three different commercial ELISA kits in order to validate its use for reindeer and CvHV-2.

Methods: Three commercial bovine ELISA kits (A, B and C), using either indirect (A) or blocking (B and C) ELISA techniques to detect antibodies against BoHV-I were tested with sera from I54 reindeer in order to detect antibodies against CvHV-2. A Spearman's rank-based coefficient of correlation $(\rho)$ was calculated. A dilution trial was performed for all kits. A virus neutralization test using both BoHV-I and CvHV-2 was carried out.

Results: Seroprevalence was almost the same with all kits (40-41\%). Despite a similar qualitative score, quantitatively kits classified samples differently and a strong correlation was only identified between Kits B and C. Blocking kits performed better in both repeatability and in the dilution trial. The virus neutralization results confirmed the ELISA results to a very high degree. Neutralizing titres ranged from I:2 to $\mathrm{I}: 256$ and from 0 to $\mathrm{I}: \mathrm{I} 6$ against CvHV-2 and BoHV-I respectively.

Conclusion: Results show that the genetic and antigenic similarity between BoHV-I and CvHV-2 enables the use of a bovine gB blocking ELISA kit to screen reindeer. The use of an ELISA kit is both cheaper and time saving, allowing screening of large populations. This study revealed a high number of positive animals against CvHV-2 and its impact and distribution in the general population should be further evaluated.
\end{abstract}




\section{Background}

Viruses in the genus Varicellovirus (family Herpesviridae subfamily Alphaherpesvirinae) are known to infect and cause disease in several ruminant species. Of the alphaherpesviruses infecting ruminants bovine herpesvirus type 1 (BoHV-1), causing the diseases Infectious Bovine Rhinotracheitis (IBR) and Infectious Pustular Vulvovaginitis (IPV), is well-described $[1,2]$. Other viruses of this genus related to BoHV-1 are known to cross-react serologically and have been isolated from semi-domesticated and wildlife ruminant species such as cervid herpesvirus 2 (CvHV-2, also known as Rangiferine Herpesvirus, RanHV) from semi-domesticated reindeer (Rangifer tarandus tarandus) in Finland and Sweden [3,4]. Serological evidence of alphaherpesvirus infection in reindeer has further been reported in Greenland [5] and Alaska [6] as well as in both wild [7] and semi-domesticated reindeer [8-10] in Norway, although it is unknown which alphaherpesvirus is circulating in these populations.

Finnmark County in northern Norway (55 $047 \mathrm{~km}^{2}$ ) is the largest reindeer herding area in Norway with an estimate of 168779 animals in 2005/2006 [11]. In this area the reindeer are kept in a semi-nomadic way being herded between summer and winter pastures, and being usually free-ranging within the borders of their specific herding districts. Mortality rates in reindeer in Finnmark vary significantly between years and reached $47 \%$ for calves in 2005-2006 [11]. The impact of CvHV-2 in reindeer mortality or abortion, events commonly associated with other alphaherpesvirus infections in ruminants [12], remains unknown.

In Norway the last BoHV-1 infection in cattle was reported in 1993 [13], and the country has officially eradicated IBR/IPV although a surveillance program is still ongoing. According to previous serosurveys $[9,10]$, alphaherpesvirus infections are suspected in semi-domesticated reindeer in Finnmark, which is of great epidemiological importance since cross-species infections between bovines and reindeer have been shown for BoHV-1 and CvHV-2 [12].

Many countries use sero-epidemiological surveys of bovine populations to maintain an active surveillance or to eradicate IBR/IPV. Different methods for screening for antibodies against BoHV-1 in cattle have been developed in several countries. In a study comparing serological BoHV-1 tests, a blocking Enzyme Linked Immunosorbent Assay (ELISA) based on glycoprotein B (gB) antigen was found to be the best option with a sensitivity of $96 \%$ and a specificity of $99 \%$ [14]. This was a better score than other blocking ELISAs based on other glycoprotein antigens (glycoprotein E), indirect ELISAs or virus neutralization tests (VNT) [14].
Glycoprotein B plays a decisive role in the interaction between the virus and host cells during the attachment, penetration and replication processes of the virus [12]. The nucleotide sequence encoding $\mathrm{gB}$ is highly conserved between BoHV-1 and CvHV-2 [15,16].

Serological cross-reactions have been shown to exist between different viruses within the Varicellovirus genus and several studies have calculated coefficients of antigenic similarity $(\mathrm{R})$ proving the serological cross-reactivity between CvHV-2 and BoHV-1 [17-20].

Given the serological cross-reactions within this genus, serological tests for BoHV-1 based on highly conserved antigen, such as $\mathrm{gB}$, could be used to detect the presence of antibodies against alphaherpesviruses in non-bovine ruminant host species. Since these viruses generally establish latency and life-long infections in their natural hosts, the presence of antibodies most likely indicates that the animals are persistently infected.

There are no standardized methods to conduct serological testing of reindeer populations and different serological techniques have been used in smaller sero-surveys carried out in Alaska [6,21], Norway [7-10] and Greenland [5]. Simultaneously, IBR/IPV eradication campaigns have many times neglected the status of wild animals as possible reservoir species for alphaherpesviruses.

To assess the present alphaherpesvirus infection status of reindeer from different reindeer husbandry districts in Finnmark, a reliable and feasible serological test was needed. Three commercial ELISA kits for detecting antibodies against BoHV-1 in cattle were evaluated regarding their ability to detect antibodies against alphaherpesviruses in reindeer: one indirect ELISA with BoHV-1 as antigen, and two blocking ELISA kits with BoHV-1 gB as antigen.

\section{Methods \\ Origin of samples}

A total of 154 serum or plasma samples from four geographically separated herds from Finnmark County, representing adults and calves as well as both genders, were collected in 2004-2005.

\section{Serological testing}

The samples were analyzed in duplicate in all the three commercial kits. The main characteristics for these kits (A, $\mathrm{B}$ and $\mathrm{C}$ ) are presented in Table 1. The manufacturer's instructions and kit components were used in Kits B and $\mathrm{C}$, while for Kit A adaptations were necessary.

Kit A, Infectious Bovine Rhinotracheitis (IBR-Ab) SVANO$\operatorname{VIR}^{\mathrm{TM}}$ (Svanova Biotech AB Sweden), is an indirect ELISA. 
Table I: Major characteristics and modifications of the three commercial bovine ELISA kits used to test reindeer for alphaherpesvirus antibodies in this study.

\begin{tabular}{|c|c|c|c|c|c|c|}
\hline & ELISA type & Well antigen & 2nd antibody & $\begin{array}{l}\text { Revelation } \\
\text { system }\end{array}$ & Absorbance & Validation rules \\
\hline SVANOVA - A & Indirect & $\begin{array}{l}\text { BoHV-I unknown antigen } \\
\text { in one well and cells on } \\
\text { another. }\end{array}$ & $\begin{array}{l}\text { Rabbit anti-reindeer } \\
\text { antibody }\end{array}$ & $\begin{array}{l}\text { Streptavidin-POD + } \\
O P D\end{array}$ & $450 \mathrm{~nm}$ & 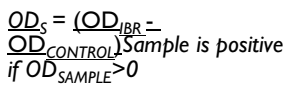 \\
\hline SYNBIOTICS - B & Blocking & BoHV-I gB antigen & $\begin{array}{l}2 \text { monoclonal antibodies } \\
\text { (Mabs) anti-gB/ } \\
\text { peroxidase }\end{array}$ & Peroxidase system & $\begin{array}{l}450 \mathrm{~nm}+620 \mathrm{~nm} \\
\text { (for correction) }\end{array}$ & $\begin{array}{l}\text { Validation rules: \%P }= \\
{\left[\left(\underline{O D}_{N}-\underline{O D_{P}}\right) / O D_{N}\right] \times 100} \\
>80 \% \text { and } O D_{N}>0,500 \\
\text { Sample is positive if: \%S }= \\
{\left[\left(\underline{O D}_{N}-\frac{O D_{S}}{S}\right) /\left(\underline{O D}_{N}-\right.\right.} \\
\left.\left.{\underline{O D_{P}}}\right)\right] \times 100>60 \\
\text { Sample is doubtful if: } \\
45<\% S<60\end{array}$ \\
\hline LSI - C & Blocking & BoHV-I gB antigen & $\begin{array}{l}\text { I monoclonal antibody } \\
\text { anti-gB/HRP labelled }\end{array}$ & $\begin{array}{l}\text { Horseradish } \\
\text { Peroxidase }\end{array}$ & $\begin{array}{l}450 \mathrm{~nm}+620 \mathrm{~nm} \\
\text { (for correction) }\end{array}$ & 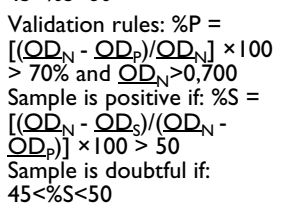 \\
\hline
\end{tabular}

BoHV-I: Bovine herpesvirus type I

gB: Glycoprotein B

OPD: orthophenyldiamine

${ }_{O D_{N}}$ : Mean optical density of the negative control sera

OD $_{\mathbf{p}}$ : Mean optical density of the positive control sera

OD $_{\mathbf{S}}$ : Mean optical density of the sample sera

Changes of the protocol to adapt the kit to reindeer are depicted in italic.

The test wells are coated with a mixture of viral and cellular proteins from virus-infected cells whereas control wells are coated with material from non-infected cells of identical type. The test serum samples were diluted 1:25 and added to test and control wells. Kit $\mathrm{A}$ is based on an indirect method, and because of this the secondary antibodies provided with the kit (horseradish peroxidase conjugated anti-bovine IgG monoclonal antibodies) could not be used, as they would not recognize reindeer antibodies. They were therefore replaced by a biotin labeled rabbitanti-reindeer antibody in a 1:200 dilution and incubated for $1 \mathrm{~h}$ at $37^{\circ} \mathrm{C}$ [22]. Revelation was achieved using Streptavidin- $\beta$ peroxidase (POD-conjugate) diluted 1:10000 (Roche $e^{\circledast}$ Mannheim, Germany) and incubated for $1 \mathrm{~h}$ at $37^{\circ} \mathrm{C}$, followed by orthophenyldiamine (OPD) as substrate (DakoCytomation ${ }^{\circledR}$ Glostrup, Denmark) incubated for $10 \mathrm{~min}$ in the dark at $20^{\circ} \mathrm{C}$. The enzyme reaction was stopped by adding $100 \mu \mathrm{L}$ of $1 \mathrm{M} \mathrm{H}_{2} \mathrm{SO}_{4}$ per well.

Because positive and negative controls of the ELISA kit were from cattle, they could not be used in an indirect ELISA method where the secondary antibody was replaced. The validation criteria proposed by the manufacturer could hence not be used, and samples were therefore considered positive when the mean OD of the antigen well minus the mean OD of the control well was above zero, which indicates a higher reaction in the antigen well compared to the control well.

Kit B, SERELISA ${ }^{\mathrm{TM}}$ IBR/IPV gB Ab Mono Blocking (SYNBIOTICS EUROPE SAS, France) is a blocking ELISA in which two peroxidase conjugated monoclonal antibodies against the gB protein of BoHV-1 compete with the serum sample antibodies in binding to $\mathrm{gB}$ antigens in the well. The negative and positive control sera from cattle supplied with the kit were used. The test serum samples were diluted 1:2. A competition percentage was calculated based on the relation between the OD mean of the duplicates and of the controls. Samples with a competition percentage above $60 \%$ were considered seropositive, between $45-60 \%$ doubtful and below $45 \%$ seronegative, as recommended when testing cattle serum samples.

Kit C, gB BLOCKING LSI ${ }^{\mathrm{TM}}$ (LSI, France - Laboratoire Service International), is based on the same blocking design as Kit $\mathrm{B}$, but with one monoclonal antibody against the $\mathrm{gB}$ protein of BoHV-1 labeled with horseradish peroxidase (HRP). The negative and positive control sera from cattle supplied with the kit were used and test serum samples were diluted 1:2. A competition percentage was calculated as for Kit B. Samples with a competition percentage above $50 \%$ were considered seropositive, between $45-50 \%$ doubtful and below 45\% seronegative, as recommended for cattle.

\section{Sample dilution curves}

In order to verify the analytical sensitivity of these kits, a serial dilution of a panel of four selected serum samples was performed in parallel for each kit. The starting point was the initial serum dilution used for each kit (1:25 in Kit $A$ and 1:2 in Kits B and C). A twofold dilution was conducted, in Kit A from 1:25 to 1:3200, and in Kits B and C from $1: 2$ to $1: 256$. The four samples chosen were all from herd IV: serum sample 24 was strongly positive in all kits; 
serum sample FA16 was moderately positive in all kits; serum sample FA15 was classified as doubtful in Kit B and seronegative in Kits A and C, and serum sample FB15 was negative in all kits.

For Kits $\mathrm{B}$ and $\mathrm{C}$ the respective positive and negative control sera from cattle were also tested. For Kit A an additional sample of water was added as a negative control and diluted as the other samples using the kit's dilution buffers.

All dilutions were tested in duplicate and mean optical density (OD) values were obtained according to the kit's specifications and used for calculations.

\section{Virus neutralization test (VNT)}

Given the serological cross-reaction between BoHV-1 and CvHV-2 and considering that the ELISA kits were designed for cattle, VNT was performed on all the reindeer serum samples to further validate the use of these kits in reindeer and to confirm their ability to detect antibodies against CvHV-2.

Reindeer sera were two fold diluted and each dilution (from $1: 2$ to $1: 256$ ) was incubated with 100 TCID $_{50}$ of CvHV-2 or BoHV-1 at $37^{\circ} \mathrm{C}$ for $1 \mathrm{~h}$.

A mixture of serum and virus $(50 \mu \mathrm{l})$ was added to wells in 96 well plates. To each well, $100 \mu$ l of Madin-Darby bovine kidney cells (MDBK), with calculated area coverage of $100 \%$, was added. The medium used was Earles MEM with addition of $2 \%$ foetal calf serum (FCS) and $2 \%$ penicillin-streptomycin (PS 10000 Units/mL penicillin and $10 \mathrm{mg} / \mathrm{mL}$ streptomycin, SIGMA-ALDRICH, Oslo

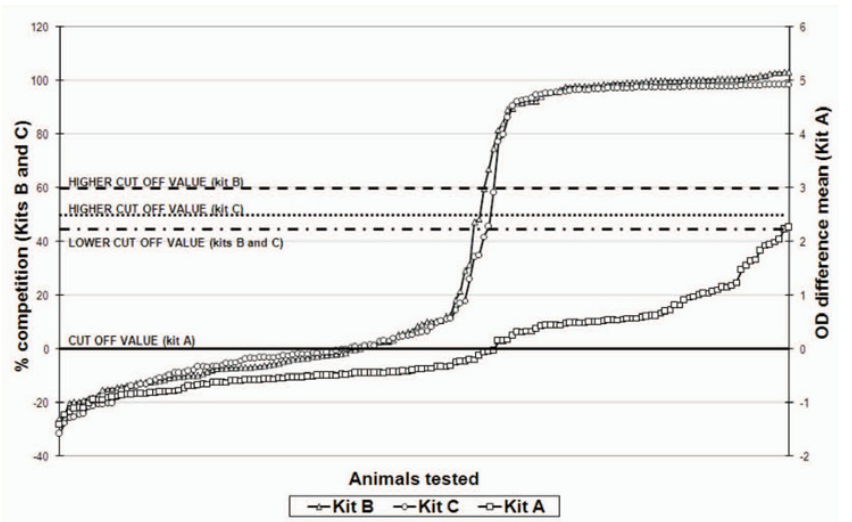

\section{Figure I}

Serology results. Serology results for 154 samples of semidomesticated reindeer from Finnmark County, Norway displayed in ascending OD for $\mathrm{Kit} A$ and in ascending competition percentage for Kits $B$ and $C$.
Norway). The plates were incubated for 2 days and then stained according to manufacturer's protocol (Diff-Quik Staining Protocol, Hamilton Thorne Research). Reading was performed and titres expressed as the reciprocal of the highest serum dilution that completely prevented a cytopathic effect (CPE). A reindeer serum sample, obtained from an animal experimentally infected with CvHV-2, and a bovine serum sample, obtained from a bovine infected with BoHV-1, were added as positive controls and used to calculate the coefficient of antigenic similarity (R) as previously described by Lyaku et al. [18].

\section{Statistical analysis}

As all samples were tested in duplicates, repeatability was assessed using the absolute difference between the OD values (variability) calculated for each sample in each kit.

As the distribution of absolute difference was highly skewed, the 5-95\% quantiles (i.e. an interval including $90 \%$ of observations with $5 \%$ on either side) were used instead of standard deviation to describe distribution of individual values.

Because using ranks resulted in more robust statistics [23], we used Spearman correlation $(\rho)$ to assess the relationships between kits. Calculations were done for two subsamples: observations below and above the cut off lines to assess the relationships between the different kits for the populations of negative versus positive samples in general and around the cut-off values. The squared value $\rho^{2}$ can be interpreted in terms of predictive power (explained variability) of one kit's ranks by the other kit's ranks. P-value was considered significant if below 0.05 . All calculations were done in R (R Development Core Team 2008).

\section{Results \\ Serological testing}

The three ELISA kits produced very similar seroprevalences results. Kit A classified 62 reindeer as having antibodies against alphaherpesvirus (40.3\%); Kit B 64 seropositive reindeer $(41.6 \%)$ and three classified as doubtful and Kit C 63 seropositive reindeer (41.0\%) with one animal classified as doubtful. Results were arranged in ascending order according to OD difference mean values for Kit A and to competition percentages for Kits B and $\mathrm{C}$ (Figure 1). The curves confirm that the individual results were distributed following a sigmoid curve for all three kits, although a more flattened curve was produced by Kit A. For Kits B and C most individuals were clustered in two distinct groups, one up to $20 \%$ of competition, representing the negative samples, and the other from $85 \%$ upwards, representing the individuals classified as seropositive. 

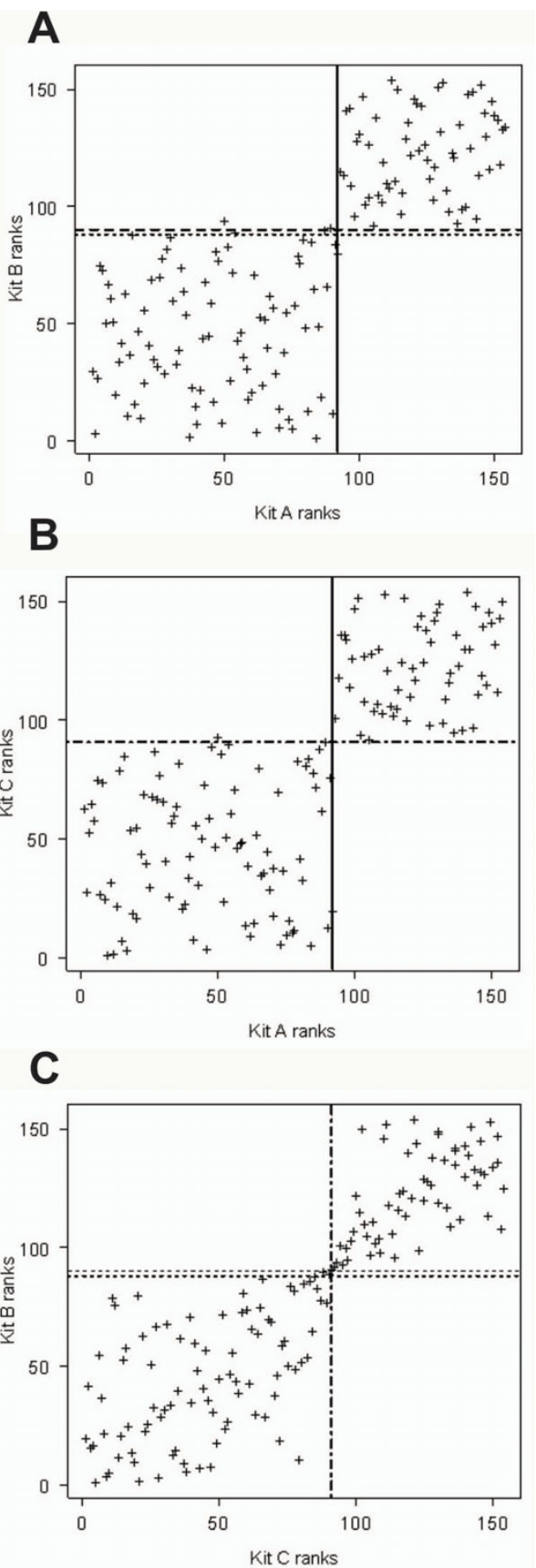

\section{Figure 2}

Comparison of three serological kits for detecting antibodies against alphaherpesvirus in reindeer by the ranks of the results. The comparison of the kits two by two was done by plotting ranks after sorting the results (OD values for Kit $A$ and competition percentage for $\mathrm{Kit} B$ and $\mathrm{C}$ ) in ascending order. Results were given a rank position: | ${ }^{\text {st }}$ rank being the most negative and $154^{\text {th }}$ rank the most positive. The graphs display the rank obtained per animal in each kit. Lines pass through the rank closest to the cut-off values for each kit (Kit A cut off value 0; Kits B and C lower cut off value $45 \%$; Kit B higher cut off value $60 \%$; Kit $C$ higher cut off value $50 \%)$. For Kit $A$, a line $(-)$ passes through the $92^{\text {nd }}$ rank $(-0.03 \mathrm{I})$. For Kit $B$, a line $(\cdots)$ passes through the $88^{\text {th }}$ rank $(47.28 \%)$ and another $(--)$ passes through the $90^{\text {th }}$ rank $(59.60 \%)$. For Kit $\mathrm{C}$, a line $(---)$ passes through the 9 Ist rank (45.54\%) and represents both cut-off values (higher and lower) as no samples were ranked in between. 2A: scatter plot displays Kit $A$ and Kit B correlation. 2B: scatter plot displays Kit A and Kit C correlation. 2C: scatter plot displays Kit B and Kit C correlation. 
Both positive and negative controls for Kit $\mathrm{B}$ and $\mathrm{C}$ scored well above the manufacturer's required thresholds.

To reveal if different kits were presenting similar qualitative results (positive, negative or doubtful) a scatter plot, displaying the results for each animal in each kit compared two by two, was constructed (not displayed). Comparing Kits $\mathrm{B}$ and $\mathrm{C}$ three animals were classified as doubtful in Kit B and seronegative in Kit $\mathrm{C}$, and one animal was seropositive in Kit B and classified as doubtful in Kit C. Comparing Kit A and B two animals were classified seronegative in Kit $\mathrm{A}$ and seropositive in Kit $\mathrm{B}$, whereas three animals were classified negative in Kit $\mathrm{A}$ and doubtful in Kit B. Comparing Kit A and C one animal was classified seronegative in Kit A and doubtful in Kit C.

Spearman coefficients (variability of one kit's ranks explained by the other kit's ranks) showed that, despite an almost absolute agreement of qualitative results (samples being classified as positive, negative or doubtful) between the kits, the quantitative results were not as concurrent (Figure 2 and Table 2). In fact, only between Kits B and C (Figure 2C) was there evidence for a strong correlation in ranks both for negative as well as positive samples $(\mathrm{P}<$ $0.001)$. A restricted analysis of samples in the slope of the curve, shown in Figure 1 (approximately ranks between $68^{\text {th }}$ and $111^{\text {th }}$ in Figure 2 ), confirmed the general observations. A correlation was evident between Kits B and C for which two clear sub-populations, negative and positive, outflanking the cut-off value were identified and confirmed by VNT. No evidence for a correlation was found within seropositive or seronegative animals by other kit comparisons (Figure 2A and 2B) apart from a weak positive association within positive results for Kit $\mathrm{A}$ and Kit $\mathrm{B}$ (Figure 2A), ( $=0.049$; all other $P$-values $>0.09$, Table 2).

\section{Repeatability analysis}

Kit A had the highest variability between OD duplicates with a maximum difference in optical density of 2.35 and a mean difference of 0.37 (5-95\% quantiles: [0.018; $1.188])$. Kit $\mathrm{B}$ had a maximum difference of 0.30 and a mean of 0.03 (5-95\% quantiles $[0.001 ; 0.160])$ and Kit C a maximum difference of 0.27 and mean of 0.06 (5-95\% quantiles $[0.001 ; 0.123])$.

\section{Serial dilution results}

Serial dilution curves are displayed in Figure 3. The curves for Kit A (Figure 3A) displayed some inconstant results for the first dilutions. The curves for Kits $\mathrm{B}$ and $\mathrm{C}$ (Figure $3 \mathrm{~B}$ and 3C) were comparable to each other. Serum sample 24 (positive in all kits) was classified as positive in all dilutions while the serum sample FA16 (also classified positive for all kits) became negative at dilution 1:32, 1:64 and 1:200 for Kits C, B and A, respectively. Positive control samples (Kits $\mathrm{B}$ and $\mathrm{C}$ ) became negative at a dilution of $1: 128$ in Kit B and $1: 8$ in Kit C.

\section{Virus neutralization results}

The VNT confirmed the ELISA results. All samples that were classified negative by all the three ELISA kits failed to neutralize any of the viruses. All samples classified positive in all kits neutralized CvHV-2, and some of them also neutralized BoHV-1 though at a lower titre. Neutralizing titres ranged for CvHV-2 from 1:2 to 1:256 and for BoHV1 from 0 to $1: 16$. No reindeer serum sample neutralized BoHV-1 to a higher titre than CvHV-2 and the biggest difference observed between a sample neutralization of CvHV-2 versus BoHV-1 was of 5 dilutions steps. Samples that were classified as doubtful in the ELISA kits were subsequently retested and classified as negative, and when tested in the VNT they also failed to neutralize any of the viruses. Only one weak positive sample in Kit B, which was doubtful in Kit $\mathrm{C}$ and negative in A failed to neutralize CvHV-2, while one sample classified as negative in Kit A but as positive in the other two kits had a low titre for CvHV-2 (1:2). The reindeer positive control neutralized CvHV-2 up to $1: 128$ and BoHV-1 up to $1: 16$ while the bovine positive control neutralized BoHV-1 up to $1: 32$ and CvHV-2 only at 1:2. The coefficient of antigenic similarity between CvHV-2 and BoHV-1 was of $\mathrm{R}=8.8$. Results are summarized in Table 3.

\section{Discussion}

Serological results obtained with the three different kits showed that the blocking design kits performed better than the indirect ones as had been concluded for the use of similar kits for BoHV-1 [14], and identified that an alphaherpesvirus serologically related to BoHV-1 is present in semi-domesticated reindeer in Finnmark. The blocking kits were found to work efficiently without any changes to the manufacturers' protocols or pre-defined cut-off values unlike Kit A which could not be used without adaptations.

Data obtained in the virus neutralization strongly indicates that CvHV-2 is most likely the virus present in this reindeer population.

The percentage of seropositive reindeer ranged from 40$42 \%$ between kits. The low variation between the kits verified the consistency of the results. In this study, reindeer samples were tested in serological kits designed for bovine sera and it was therefore necessary to verify if the preestablished cut off values could be used for reindeer sera. From the data obtained in the kits with blocking design (B and $\mathrm{C}$ ) even considerable changes in the cut off values (10\% up or downwards) would not significantly change the results.

The Spearman coefficient is based on the ranks, reducing sensitivity to outliers that could affect the Pearson correlation coefficient. The value of Spearman's $\rho$ calculated for each sub-populations of positive or negative results, 
showed that there was an association between ranks when the two blocking kits were compared as could have been expected given they were based on the same blocking ELISA design. Samples tended to score similar percentages of competition for Kits B and C even when we analyzed only those samples flanking the cut-off lines. The clustering in two populations above and below the cut-off line with similar quantitative and qualitative results was shown to be concurrent with the VNT results with the exception of two samples.

Despite using a different method, Kit A showed qualitative results (animal classified as positive or negative) very similar to the other two kits. Some association within positive results between Kits A and B further showed that the tested ELISA kits correctly classified samples even when using different methods.

Regarding the samples that scored negative in Kit A while positive or doubtful in Kits B and C, one could also consider that the difference may be due to a non specific inhibitory character in the sera or a possible difference in available epitopes for reaction between the two ELISA methods.

The analysis of variability serves as an important tool to study repeatability, and the differences between samples tested in duplicate in the same plate is a good evaluator. A mean variability in OD of $0.06(5-95 \%$ [0.001; 0.123]) for Kit $C$ and of 0.03 (5-95\% [0.001; 0.160]) for Kit B are good evidences that gB blocking kits had a better repeatability compared to the indirect ELISA (Kit A), which had a mean variability in OD of $0.37(5-95 \%[0.018 ; 1.188])$. It is however important to remember that a direct comparison is difficult since the protocol of Kit $\mathrm{A}$ had to be adapted to test reindeer sera. In Kits B and C variability was obtained from the absolute difference between the observed OD for a given sample $\left(\left|\mathrm{OD}_{\mathrm{S} 1}-\mathrm{OD}_{\mathrm{S} 2}\right|\right)$, where $\mathrm{S} 1$ and S2 represent the duplicates of a given test sample. In Kit A however, there was an intermediate step for the calculation of the same value $\left(\mid\left(\mathrm{OD}_{\mathrm{IBR} 1}-\mathrm{OD}_{\mathrm{CONTROL} 1}\right)-\right.$ $\left.\left(\mathrm{OD}_{\mathrm{IBR} 2}-\mathrm{OD}_{\mathrm{CONTROL} 2}\right) \mid\right)$, where $\mathrm{CONTROL}$ represents the control wells, ${ }_{\mathrm{IBR}}$ the well containing the antigen and 1 and 2 the duplicates. This additional step in Kit A might also have contributed to the higher variability in Kit A versus Kits B and C.

If we consider that analytical sensitivity is the largest dilution of a high-level positive serum in which antibody is no longer detected, we observed a similar pattern for all kits, in which sample 24 remained positive at 1:256 for Kits B and $C$ and at 1:3200 for Kit A. Sample FA16, which was another strong positive (though not as strong as number 24), became negative at 1:200, 1:64, 1:32 for Kits A, B and $\mathrm{C}$ respectively.

The abnormal curve observed in Kit A (Figure 3A) was repeated and confirmed and could possibly be explained by unspecific factors in the sera which interfered with the binding of the antibodies.

Given the reduced number of samples tested it is difficult to present a final conclusion for sensitivity, but we might conclude for Kits B and C that they have a good sensitivity as positive samples are still detectable 3 to 4 dilution steps below their testing dilution. Further, it is possible to conclude from the three serial dilution curves, that the blocking design kits presented a more stable curve with a moderate decrease in competition percentage when compared to the indirect ELISA kit where OD values changed abruptly and oscillated even though sensitivity also seemed to be high considering how the positive samples scored.

Table 2: Spearman correlation analysis within positive and negative results for the three commercial bovine ELISA kits tested, compared two by two.

\begin{tabular}{|c|c|c|c|}
\hline Kits compared & Population analysed & $\rho$ & $\mathbf{P I}^{\prime}$ \\
\hline \multirow[t]{2}{*}{ Kit $A$ and $B$} & $\begin{array}{c}\text { Negative } \\
\left(<88^{\text {th }} \text { rank for Kit } B \text { and }<92^{\text {nd }} \text { rank for Kit } A\right)\end{array}$ & 0.032 & 0.767 \\
\hline & $\begin{array}{c}\text { Positive } \\
\left(>90^{\text {st }} \text { rank for Kit B and }>92^{\text {nd }} \text { rank for Kit } A\right)\end{array}$ & 0.247 & 0.049 \\
\hline \multirow[t]{2}{*}{ Kit $A$ and $C$} & $\begin{array}{c}\text { Negative } \\
\left(<\left.9\right|^{\text {st }} \text { rank for Kit } C \text { and }<92^{\text {nd }} \text { rank for Kit } A\right)\end{array}$ & -0.003 & 0.974 \\
\hline & $\begin{array}{c}\text { Positive } \\
\left(>\left.9\right|^{\text {st }} \text { rank for Kit } C \text { and }>92^{\text {nd }} \text { rank for Kit } A\right)\end{array}$ & 0.213 & 0.093 \\
\hline \multirow[t]{2}{*}{ Kit $B$ and $C$} & $\begin{array}{c}\text { Negative } \\
\left(<88^{\text {th }} \text { rank for Kit } B<9 \mid \text { st rank for Kit } C\right)\end{array}$ & 0.481 & $<0.001$ \\
\hline & $\begin{array}{c}\text { Positive } \\
\left(>90^{\text {th }} \text { rank for Kit B and }>\left.9\right|^{\text {st }} \text { rank for Kit C) }\right.\end{array}$ & 0.593 & $<0.001$ \\
\hline
\end{tabular}

I P-value is considered significant if below 0.05 


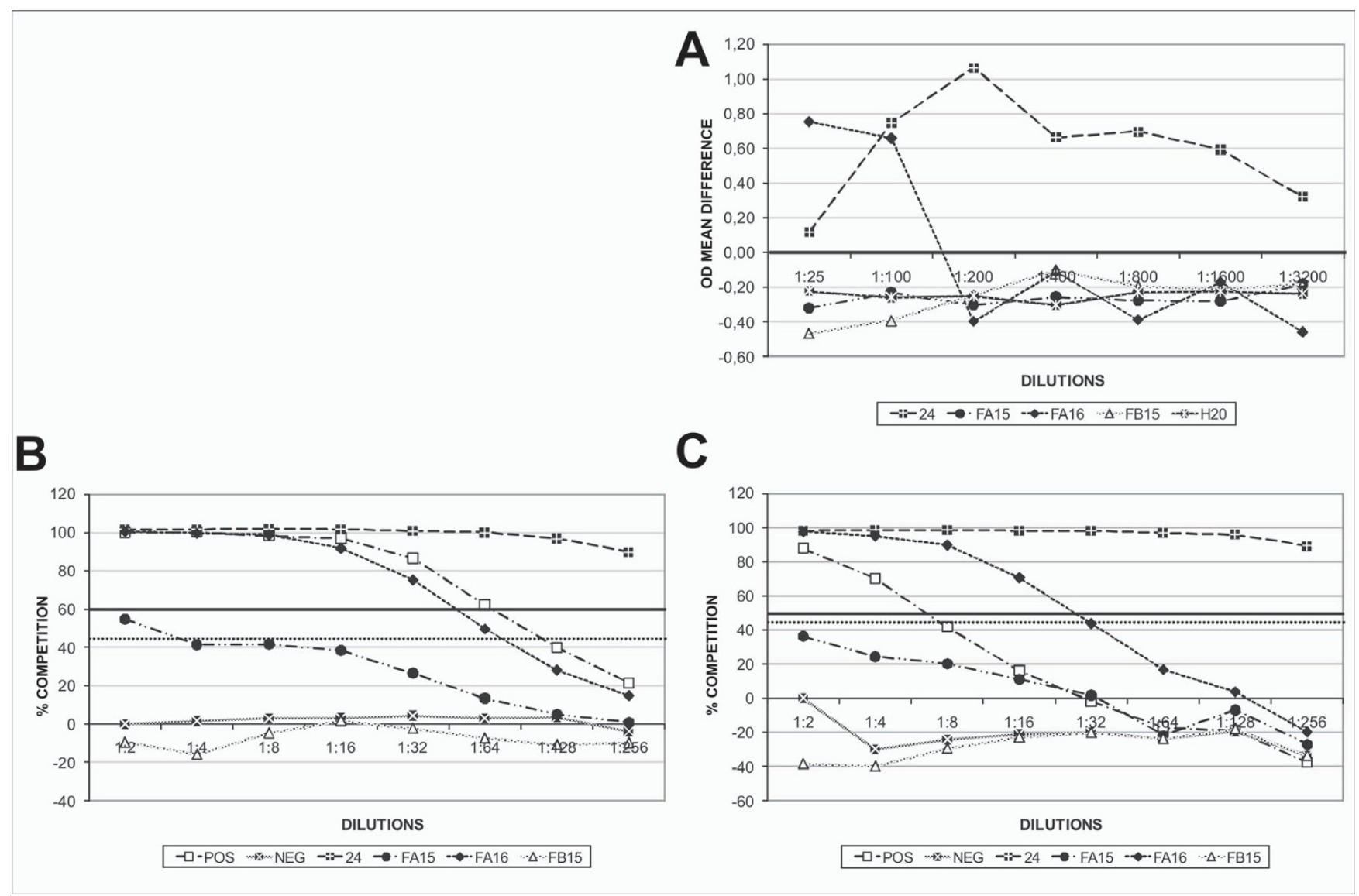

Figure 3

Serial dilution curves of a panel of reindeer serum samples tested in three commercial bovine ELISA kits for detection of alphaherpesvirus antibodies. Four samples were selected to illustrate different situations: Serum samples 24 and FAI 6 were seropositive in all kits; serum sample FAI5 was found to be doubtful in Kit B and seronegative in Kits A and C; serum sample FBI5 was classified negative in all kits. The positive and negative cattle sera controls from Kits $B$ and $C$ were also titrated. In Kit $A$ there were no controls, but water was tested as a negative control. $3 \mathrm{~A}, 3 \mathrm{~B}$ and $3 \mathrm{C}$ displays Kits $\mathrm{A}, \mathrm{B}$ and $\mathrm{C}$ serial dilutions respectively. In Figure $3 A$ a continuous bold line $(-)$ indicates the cut-off value for Kit $A(0.00)$. In Figures $3 B$ and $3 \mathrm{C}$ a continuous bold line $(-)$ indicates the upper cut-off value for the kits $(60 \%$ for Kit $\mathrm{B}$ and $50 \%$ for Kit $\mathrm{C})$ while a dotted bold line ( $\cdots)$ indicates the lower cut-off values ( $45 \%$ for both kits).

When comparing the ELISA designs used in this study, it is demonstrated from the serology but also from the variance and serial dilution analysis that the gB blocking design kits should be preferred to the indirect ELISA kit. This was also the situation when testing cattle, where the BoHV-1 gB kits was found more suitable as compared to kits with an indirect ELISA design [14,24-26]. The lower performance of Kit A in this trial may have derived from the adaptations introduced and the conclusions drawn are therefore only valid regarding its adaptation to test reindeer sera as required by the aim of this study.

When comparing the two blocking ELISA kits little differences can be found, though Kit $\mathrm{C}$ gave less doubtful results and a slightly better repeatability. The positive control serum of Kit $\mathrm{C}$ performed however worse in the dilu- tion analysis compared to the positive control of Kit B, becoming negative at dilutions of $1: 8$ and 1:128 respectively.

Regarding the VNT, Kramps et al. [14] clarified that VNT did not present sufficient advantages to be the method of choice for cattle. They showed that the ELISA kits had a higher sensitivity and specificity and that they were time and cost saving when large numbers of samples were to be tested.

Even though the ELISA kits compared in this study were designed for cattle, the genetic similarity between BoHV-1 and CvHV-2 was sufficient for all kits to detect reindeer antibodies against CvHV-2. The VNT confirmed this by showing an unequivocal higher neutralization against 
Table 3: Virus neutralization test (VNT) on reindeer sera tested in this study.

\begin{tabular}{|c|c|c|c|c|c|c|}
\hline \multicolumn{3}{|c|}{ ELISA Kits results } & \multicolumn{2}{|c|}{ No. of samples } & \multirow{2}{*}{$\begin{array}{c}\begin{array}{c}\text { Neutralizing antibody titre } \\
\text { [min and max titre] average }\end{array} \\
\text { BoHV-I }\end{array}$} & \multirow{2}{*}{$\begin{array}{c}\text { Difference between CvHV-2 and BoHV-I } \\
\text { in dilution steps } \\
{[\mathrm{min}-\mathrm{max}] \text { average }}\end{array}$} \\
\hline $\mathbf{A}$ & B & C & & CvHV-2 & & \\
\hline+ & + & + & 62 & {$[1: 2-1: 256] \quad 1: 45$} & {$[0-16]$ I:3 } & {$[1-5] 3.2$} \\
\hline- & \pm & - & 3 & [0] & [0] & 0 \\
\hline- & + & \pm & I & {$[0]$} & [0] & 0 \\
\hline- & + & + & 1 & {$[1: 2]$} & [0] & 1 \\
\hline- & - & - & 87 & {$[0]$} & {$[0]$} & 0 \\
\hline+ & + & + & Bovine + control & {$[1: 2]$} & {$[1: 32]$} & 4 \\
\hline+ & + & + & Reindeer + control & {$[1: 128]$} & {$[1: 16]$} & 3 \\
\hline
\end{tabular}

Neutralizing titres are expressed as the reciprocal of the highest serum dilution that completely prevented a cytopathic effect (CPE). For each virus neutralization, the maximum and minimum titres obtained in each group of samples are presented. Samples were grouped according to the results they obtained in the different ELISA kits ( + for positive; \pm for doubtful; - for negative). [0] represents the absence of neutralization. The difference between the neutralizing titres against CvHV-2 and BoHV-I is presented in dilution steps differences.

CvHV-2 with an average difference of three dilution steps to BoHV-1. Neutralization against other alphaherpesviruses was not performed in this study given their unlikely presence in Norway.

The VNT further showed that the cut-off values of the ELISA kits were placed at a correct percentage of competition for Kits B and C and correct OD value for Kit A. Samples classified as doubtful (Kits $\mathrm{B}$ and $\mathrm{C}$ ) where negative in the VNT and only one low positive in Kit B (doubtful in Kit $\mathrm{C}$ ) and one negative sample in Kit A might have been misclassified by the ELISA kits, if one wishes to consider the VNT as a potential gold standard test for this type of wildlife screening.

The present coefficient of antigenic similarity of 8.8 is in line with previous calculations by Lyaku et al. and Rimstad et al. who calculated it to be 9 and 8.8 respectively, even though the titres against CvHV-2 were lower in this study (1:256 maximum) than in previous ones, where reindeer sera neutralized CvHV-2 up to 1: 1024 and 1:512 respectively $[18,20]$.

It is important to clarify that the VNT was used mostly to confirm the presence of another alphaherpesvirus than BoHV-1, as would be expected given the BoHV-1 free status in cattle in Norway, and not specifically to compare the performance of ELISA versus VNT despite the agreement found between the two types of tests.

Kits $\mathrm{B}$ and $\mathrm{C}$ used as antigen the gB glycoprotein which is strongly immunogenic and induces a humoral response that appears in an early stage of infection [27]. This response persists two to three years after infection in cattle [28]. Because of the persistence of anti-gB antibodies, as well as the fact that the $\mathrm{gB}$ antigen is genetically conserved between alphaherpesviruses of ruminants, gB can be regarded as an ideal antigen for serology in wild animals for which the time of infection is unknown and no validated serological tests are commercially available.

\section{Conclusion}

The blocking ELISA kits using gB as antigen were found to be preferable to use in serosurveys for alphaherpesvirus in reindeer. Furthermore the choice of a blocking ELISA enables all ELISA components to be used and thus gives both economical and time saving advantages.

With $40 \%$ of tested animals presenting antibodies against alphaherpesviruses, our results indicate that an alphaherpesvirus infection is present in reindeer in Finnmark County.

The virus neutralization results, associated to the inexistence of BoHV-1 in Norway, strengthened and confirmed the hypothesis that the virus present in this population is indeed CvHV-2 and that a blocking ELISA commercial kit can efficiently be used to screen reindeer for the presence of antibodies against this virus.

These results, in combination with the knowledge of the biological and economical importance of the closely related BoHV-1 infection in cattle, should encourage further studies of the distribution and impacts of CvHV-2 infection in reindeer in Scandinavia.

\section{Competing interests}

The authors declare that they have no competing interests.

\section{Authors' contributions}

$\mathrm{CDN}$ and MT designed the experiment and analyzed the data. CDN, MT and MR performed the experiment. CDN and NGY performed the statistical analysis. ER and CDN performed the virus neutralization assay. CDN, ER and 
MT, drafted the manuscript. MR and NGY further helped to draft the manuscript. All authors read and approved the final manuscript.

\section{Acknowledgements}

We would like to acknowledge the irreplaceable help in the laboratory from Eva Marie Breines and Ellinor Hareide, and in the field from the veterinary students, Ingebjørg Nymo, Veronique Poulain, Anett Larsen and Trine Marhaug. We would also like to thank the staff at Karasjok and Kautokeino slaughterhouses for their help and hospitality. Finally we would like to thank The Norwegian Institute for Nature Research for their help during the sampling of live animals in Finnmark.

This project was supported by the Norwegian Reindeer Development Fund (RUF).

\section{References}

I. Engels M, Ackermann M: Pathogenesis of ruminant herpesvirus infections. Vet Microbiol 1996, 53:3-15.

2. Pastoret PP, Thiry E, Brochier B, Derboven G: Bovid herpesvirus I infection of cattle: pathogenesis, latency, consequences of latency. Ann Rech Vet 1982, 13:22 I-235.

3. Ek-Kommonen C, Pelkonen S, Nettleton PF: Isolation of a herpesvirus serologically related to bovine herpesvirus I from a reindeer (Rangifer tarandus). Acta Vet Scand 1986, 27:299-30I.

4. Rockborn G, Rehbinder C, Klingeborn B, Lefler M, Klintevall K, Nikkilä $T$, Landèn $A$, Nordkvist $M$ : The demonstration of a herpesvirus, related to bovine herpesvirus $I$, in reindeer with ulcerative and necrotizing lesions of the upper alimentary tract and nose. Rangifer 1990:373-384.

5. Report on the animal health situation in Greenland 1999 [http://gl.foedevarestyrelsen.dk/FDir/Publications//99964l/Rap port.pdf].

6. Dieterich RA: Respiratory viruses. In Alaskan wildlife diseases Fairbanks: University of Alaska; 1981:28-29.

7. Lillehaug A, Vikoren T, Larsen IL, Akerstedt J, Tharaldsen J, Handeland $\mathrm{K}$ : Antibodies to ruminant alpha-herpesviruses and pestiviruses in Norwegian cervids. / Wildl Dis 2003, 39:779-786.

8. Hyllseth B, Stuen S, Rimstad E, Dahle HK, Tyler NJC: Serologiske undersøkelser over herpesvirus infekjoner hos rein I Finnmark og Svalbard. Nor Vet Tidsskr 1993, 105:733-736.

9. Stuen S, Krogsrud J, Hyllseth B, Tyler NJC: Serosurvey of three virus infections in reindeer in northern Norway and Svalbard. Rangifer 1993, 13:215-219.

10. Tryland M, Mørk T, Ryeng KA, Sørensen KK: Evidence of parapox, alphaherpes- and pestivirus infections in carcasses of semidomesticated reindeer (Rangifer tarandus tarandus) from Finnmark, Norway. Rangifer 2005, 25:75-83.

II. Anonymous: Ressursregnskap for Reindriftsnæringen fra Reindriftsforvaltningen. Alta: Reindriftsforvaltningen; 2007.

12. Thiry J, Keuser V, Muylkens B, Meurens F, Gogev S, Vanderplasschen $A$, Thiry E: Ruminant alphaherpesviruses related to bovine herpesvirus I. Vet Res 2006, 37:169-190.

13. Nyberg $O$, Tharaldsen J, Heier BT: The surveillance and control programme for infectious bovine rhinotracheitis (IBR) and infectious pustular vulvovaginitis (IPV) in Norway. Annual Report 2004. National Veterinary Institute, Norway 2004:54-58 [http:/ /www.vetinst.no/nor/content/download/418/3433/file/ vetinst nokrapp05 6.pdf]. 07 February 2006

14. Kramps JA, Banks M, Beer M, Kerkhofs P, Perrin M, Wellenberg G], Van Oirschot JT: Evaluation of tests for antibodies against bovine herpesvirus I performed in national reference laboratories in Europe. Vet Microbiol 2004, 102:169-181.

15. Griffin AM: The nucleotide sequence of the glycoprotein gB gene of infectious laryngotracheitis virus: analysis and evolutionary relationship to the homologous gene from other herpesviruses. J Gen Virol 1991, 72:393-398.

16. Ros C, Belak S: Studies of genetic relationships between bovine, caprine, cervine, and rangiferine alphaherpesviruses and improved molecular methods for virus detection and identification. J Clin Microbiol 1999, 37: 1247-1253.
17. Deregt D, Gilbert SA, Campbell I, Burton KM, Reid HW, Littel-van den Hurk SVD, Penniket C, Baxi MK: Phylogeny and antigenic relationships of three cervid herpesviruses. Virus Res 2005, I | 4:|40-I 48.

18. Lyaku JRS, Nettleton PF, Marsden H: A Comparison of Serological Relationships among 5 Ruminant Alphaherpesviruses by Elisa. Arch Virol 1992, I 24:333-34I.

19. Martin WB, Castrucci G, Frigeri F, Ferrari M: A serological comparison of some animal herpesviruses. Comp Immunol Microbiol Infect Dis 1990, 13:75-84

20. Rimstad E, Krona R, Hyllseth B: Comparison of Herpesviruses Isolated from Reindeer, Goats, and Cattle by Restriction Endonuclease Analysis. Arch Virol 1992, 1 23:389-397.

21. Dau J: Caribou management report Units 2ID, 22A, 22B, 23, 24 and 26A. In Caribou management report of survey-inventory activities I July 1998 - 30 June 2000 Edited by: Healy C. Juneau: Alaska Department of Fish and Game; 200I: 195-218.

22. Åsbakk K, Gall D, Stuen S: A screening ELISA for brucellosis in reindeer. Zentralbl Veterinarmed B 1999, 46(9):649-657.

23. Conover WJ, Iman RL: Rank transformations as a bridge between parametric and nonparametric statistics. American Statistician 198I, 35: 124-129.

24. Perrin B, Bitsch V, Cordioli P, Edwards S, Eloit M, Guerin B, Lenihan P, Perrin M, Ronsholt L, Van Oirschot JT, et al.: A European comparative study of serological methods for the diagnosis of infectious bovine rhinotracheitis. Rev Sci Tech 1993, I 2:969-984.

25. Kramps JA, Perrin B, Edwards S, van Oirschot JT: A European inter-laboratory trial to evaluate the reliability of serological diagnosis of bovine herpesvirus I infections. Vet Microbiol 1996, 53:153-161.

26. Kramps JA, Magdalena J, Quak J, Weerdmeester K, Kaashoek MJ, Marisveldhuis MA, Rijsewijk FAM, Keil G, Vanoirschot JT: A Simple, Specific, and Highly Sensitive Blocking Enzyme-LinkedImmunosorbent-Assay for Detection of Antibodies to Bovine Herpesvirus-I. J Clin Microbiol 1994, 32:2 I75-2I8I.

27. Schwyzer M, Ackermann M: Molecular virology of ruminant herpesviruses. Vet Microbiol 1996, 53:17-29.

28. Kaashoek MJ, Rijsewijk FAM, VanOirschot JT: Persistence of antibodies against bovine herpesvirus I and virus reactivation two to three years after infection. Vet Microbiol 1996, 53:103-110.
Publish with BioMed Central and every scientist can read your work free of charge

"BioMed Central will be the most significant development for disseminating the results of biomedical research in our lifetime. "

Sir Paul Nurse, Cancer Research UK

Your research papers will be:

- available free of charge to the entire biomedical community

- peer reviewed and published immediately upon acceptance

- cited in PubMed and archived on PubMed Central

- yours - you keep the copyright

Submit your manuscript here:

http://www.biomedcentral.com/info/publishing_adv.asp
BioMedcentral 